\title{
Umbrella Review on Associations Between Single Nucleotide Polymorphisms and Lung Cancer Risk
}

OPEN ACCESS

Edited by:

Hem Chandra Jha

Indian Institute of Technology Indore,

India

Reviewed by

Sohani Das Sharma,

Weill Cornell Medical Center,

United States

Pallavi Shrivastava,

Universidad Católica de Santa

María, Peru

*Correspondence: Yuhong Zhao

zhaoyuhong@sj-hospital.org

${ }^{\dagger}$ These authors have contributed equally to this work

Specialty section:

This article was submitted to

Molecular Diagnostics and

Therapeutics,

a section of the journal

Frontiers in Molecular Biosciences

Received: 29 March 2021

Accepted: 18 August 2021 Published: 03 September 2021

Citation:

Li X, Wu Q, Zhou B, Liu Y, Lv J, Chang $Q$ and Zhao $Y$ (2021) Umbrella

Review on Associations Between Single Nucleotide Polymorphisms and Lung Cancer Risk.

Front. Mol. Biosci. 8:687105. doi: $10.3389 /$ fmolb.2021.687105

\author{
Xiaoying $\mathrm{Li}^{1,2 \dagger}$, Qijun $\mathrm{Wu}^{1,2 \dagger}$, Baosen $\mathrm{Zhou}^{3}$, Yashu Liu ${ }^{1,2}$, Jiale $\mathrm{Lv}^{1,2}$, Qing Chang ${ }^{1,2}$ and \\ Yuhong Zhao ${ }^{1,2 *}$
}

${ }^{1}$ Department of Clinical Epidemiology, Shengjing Hospital of China Medical University, Shenyang, China, ${ }^{2}$ Clinical Research Center, Shengjing Hospital of China Medical University, Shenyang, China, ${ }^{3}$ Department of Clinical Epidemiology, First Affiliated Hospital of China Medical University, Shenyang, China

The aim is to comprehensively and accurately assess potential relationships between single nucleotide polymorphisms (SNP) and lung cancer (LC) risk by summarizing the evidence in systematic reviews and meta-analyses. This umbrella review was registered with the PROSPERO international prospective register of systematic reviews under registration number CRD42020204685. The PubMed, Web of Science, and Embase databases were searched to identify eligible systematic reviews and meta-analyses from inception to August 14, 2020. The evaluation of cumulative evidence was conducted for associations with nominally statistical significance based on the Venice criteria and false positive report probability (FPRP). This umbrella review finally included 120 articles of a total of 190 SNP. The median number of studies and sample size included in the meta-analyses were five (range, 3-52) and 4389 (range, 354-256 490), respectively. A total of 85 SNP (in 218 genetic models) were nominally statistically associated with LC risk. Based on the Venice criteria and FPRP, 13 SNP (in 22 genetic models), 47 SNP (in 99 genetic models), and 55 SNP (in 94 genetic models) had strong, moderate, and weak cumulative evidence of associations with LC risk, respectively. In conclusion, this umbrella review indicated that only 13 SNP (of 11 genes and one miRNA) were strongly correlated to LC risk. These findings can serve as a general and helpful reference for further genetic studies.

Keywords: umbrella review, lung cancer, risk, single nucleotide polymorphism, association

\section{INTRODUCTION}

Lung cancer (LC) is associated with high morbidity and mortality rates and, thus, remains a serious threat to human health (Torre et al., 2015; Siegel et al., 2020). LC is generally discovered at advanced stages due to inconspicuous symptoms at the early stage of disease and the lack of effective and convenient screening methods (Nasim et al., 2019). Therefore, risk factors and biomarkers of the carcinogenesis and progression of LC should be explored for application in screening and clinical practice. Although smoking is a major risk factor, some LC patients have no history of smoking, indicating that other factors, such as second-hand smoke, indoor air pollution, and genetic factors, can promote the onset and progression of LC (Rivera and Wakelee, 2016).

Molecular epidemiological and experimental studies have shown that genetic variations play important roles in the occurrence of LC (Malhotra et al., 2016). A single nucleotide polymorphism (SNP), which is defined as a nucleotide variation with a frequency of greater than $1 \%$ in a population, 
is the most common form of genetic variation in the human genome. A growing number of studies on relationships between SNP and LC risk have been published in recent years. Systematic reviews and meta-analyses with relatively high levels of epidemiological evidence have summarized the associations between a SNP (or certain SNP) and LC risk, because the results have been somewhat inconsistent (Lau et al., 1998). However, the associations identified by systematic reviews and meta-analyses might be not accurate owing to the influence of various factors, such as publication bias (Ioannidis, 2005).

Dong et al. evaluated the results of meta-analyses and pooled analyses along with the false positive report probability (FPRP) to summarize the genetic susceptibility to cancer and found only 11 significant associations between genetic variations and LC risk (Dong et al., 2008). Marshall et al. mainly used the results of meta-analyses to review genetic susceptibility to LC which was identified with a candidate gene approach (Marshall and Christiani, 2013). In 2017, Liu et al. utilized the Venice criteria and FPRP to evaluate the results of meta-analyses to further summarize genetic associations with the risk of LC and found only 15 SNP with strong evidence (Liu et al., 2017). However, to the best of our knowledge, an umbrella review that extracts data, rather than the results, of systematic reviews and meta-analyses to calculate and evaluate the associations between SNP and LC risk has not been reported at present. Therefore, in order to comprehensively and accurately assess the relationships between SNP and LC risk, the present umbrella review was conducted based on the Venice criteria and FPRP.

\section{METHODS}

We conducted an umbrella review, which systematically collected and evaluated systematic reviews and meta-analyses of a specific research topic (Ioannidis, 2009). The umbrella review followed the PRISMA (Preferred Reporting Items for Reviews and Metaanalysis) and MOOSE (Meta-analyses of Observational Studies in Epidemiology) guidelines (Stroup et al., 2000; Moher et al., 2009). This umbrella review was registered with the PROSPERO 2020 international prospective register of systematic reviews under the registration number CRD42020204685.

\section{Literature Search}

Eligible systematic reviews and meta-analyses published until August 14, 2020 were retrieved from the PubMed, Web of Science, and Embase databases with a combination of subject headings and free terms, as detailed in Supplementary Additional file S1. In addition, references of eligible articles were searched to avoid omissions.

\section{Eligibility Criteria}

The inclusion criteria for article eligibility were: 1) systematic reviews or meta-analyses with quantitative synthesis; 2) investigations of the association between SNP and LC risk; 3) inclusion limited to observational studies, while excluding crosssectional studies; 4) case-control studies or genome-wide association studies (GWAS) included in the meta-analyses that provided the number of cases and controls, and cohort studies included in the meta-analyses that provided the number of cases and population participants; 5) providing the genotyping data or specific relative risk estimates (risk ratio, odds ratio) with the $95 \%$ confidence interval (CI) of each included study; 6) included at least three studies; and 7) the article was written in English.

The exclusion criteria of eligible articles were: 1) included studies whose subjects were non-human, or studies without cancer-free controls; 2) included family-based studies; 3) investigations of variants with ranges greater than one SNP; 4) evaluation of the diagnosis, survival, or recurrence of LC; 5) metaanalyses or systematic reviews based on individual data; and 6) unpublished articles, published articles in abstracts only, letters to editors, and editorial comments.

If there was more than one eligible meta-analysis of the same SNP, the most recently published one (the time was subject to the deadline for including literature in the meta-analyses) with the corresponding data described in inclusion criteria 4) and 5) were retained because the most recent meta-analysis usually had the largest sample size (although sometimes smaller because of the stricter inclusion criteria) (Dong et al., 2008). If an article conducted meta-analyses of more than one SNP individually, each was assessed separately. This umbrella review was intended to include as many ethnicities as possible. Thus, the vast majority of meta-analyses included two or more ethnicities, unless a SNP was only performed meta-analyses for single ethnicity. For SNP that were ultimately rated as "strong" by evaluation of cumulative evidence, sensitivity analysis was conducted. Eligible articles were searched by two investigators individually and a dedicated investigator was responsible for quality control and decisions on inconsistencies.

\section{Data Extraction}

Two investigators separately extracted data from the eligible systematic reviews and meta-analyses and a dedicated investigator conducted quality control and resolved inconsistencies. For each eligible article, the extracted data included 1) the name of the first author, 2) year of publication, 3) examined SNP, 4) gene name, 5) the number of included studies, 6) genotyping data or specific relative risk estimates (risk ratio, odds ratio) with the $95 \%$ CI for each of the included studies (genotyping data was preferred), 7) epidemiological design (case-control study, GWAS, or cohort study) of each study, 8) the number of cases and controls (for case-control studies and GWAS) or the number of cases and population participants (for cohort studies) of each study, and 9) the probability $(p)$ value of the Hardy-Weinberg equilibrium (HWE) test for each of the included studies.

\section{Quality Assessment of Included Articles}

Two investigators separately used the AMSTAR tool to evaluate the quality of the included articles and a third investigator was responsible for quality control and resolving inconsistencies (Shea et al., 2007). The AMSTAR tool includes 11 criterion items that are scored as 1 point for a positive or 0 points for other answers. The total score is the sum of the 11 items as follows: $\geq 8$ points was considered as high quality; $4-7$ points as 
moderate quality; and $\leq 3$ points as low quality (Neuenschwander et al., 2019).

\section{Statistical Analysis}

If the HWE results of the controls were not available, the HWE was evaluated with the chi square test. As there is no consensus on an optimal genetic model for the study of SNP, five commonly used genetic models were used for analysis, unless the corresponding data for some genetic models were not available. The five commonly used genetic models included the heterozygote comparison model (model 1), the homozygote comparison model (model 2), the dominant model (model 3 ), the recessive model (model 4 ), and the allele model (model 5) (i.e., if a SNP is $1 / 2$, the heterozygote comparison model: 12 vs 11; the homozygote comparison model: 22 vs 11; the dominant model: $12+22$ vs 11; the recessive model: 22 vs $11+12$; the allele model: 2 vs 1 ).

\section{Assessment of Pooled Effects and Heterogeneity}

Fixed-effects and random-effects models were used to calculate the pooled effects with $95 \%$ CI for each meta-analysis (DerSimonian and Laird, 1986; Lau et al., 1997). For the sake of conservativeness, the main inferences were based on a randomeffects model and $p<0.05$ (random-effects model) was considered nominally statistically significant for each metaanalysis (Vineis et al., 2009). The 95\% prediction intervals of the summary effect estimates (random-effects model) were further evaluated to account for the heterogeneity between studies and suggest the uncertainty of an effect that would be expected in a new study exploring the same relationship (Higgins et al., 2009; Riley et al., 2011). Between-study heterogeneity was assessed with the Cochran $Q$ statistic and the $I^{2}$ statistic (Higgins and Thompson, 2002). For the Cochran $Q$ statistic, $p<0.10$ was considered statistically significant (Lau et al., 1997). $I^{2}>50 \%$ is often considered to indicate a large degree of heterogeneity. The 95\% CI of $I^{2}$ was calculated based on the method described by Ioannidis et al. (Ioannidis et al., 2007).

\section{Evaluation of Bias}

For SNP with nominal statistical significance, four methods were used to assess bias. First, for nominally statistically significant relationships, we examined whether the relationships were lost by excluding the first published studies (Vineis et al., 2009). Second, for nominally statistically significant relationships, we also assessed whether the associations were lost by excluding studies that violated the HWE $(p<0.05)$ (Trikalinos et al., 2006). Third, assessment of the small-study effect was conducted to determine whether relatively small studies, as compared to relatively large studies, were apt to give higher risk estimates. The asymmetry test, as described by Egger et al. (1997), was used to assess the small-study effect, which was considered to exist when: 1) the $p$-value of the Egger's test was $<0.10$ and 2) the larger studies had a more conservative effect size than the random-effects meta-analysis (Carvalho et al., 2016). Fourth, assessment of excess significance was performed using the Ioannidis test (Ioannidis and Trikalinos, 2007). Briefly, evaluation of excess significance was to compare the observed number of studies of nominally significant results $(\mathrm{O})$ with the expected number of significant results (E). Excess significance was considered to exist when the $p$-value of the Ioannidis test was $<0.10$ and $\mathrm{O}>\mathrm{E}$. All analyses were two-sided and performed with Stata 11 software (Stata LLC, College Station, TX, United States).

\section{Evaluation of Cumulative Evidence}

The cumulative evidence of SNP with nominal statistical significance was further evaluated. First, the strength of the evidence, as an indicator of epidemiological credibility, was evaluated using the Venice criteria (Ioannidis et al., 2008) that have been applied in previous studies (Vineis et al., 2009; Giannakou et al., 2018; Yang et al., 2019). The grading criteria included three items (amount of evidence, replication, and protection from bias), which were rated as $\mathrm{A}, \mathrm{B}$, or $\mathrm{C}$, as described in detail in Table 1. If the sample size of the rarer allele in a meta-analysis could not be directly obtained, the value was calculated based on the minor allele frequency (MAF) retrieved from the SNP database of the National Center for Biotechnology Information (https://www.ncbi.nlm.nih.gov/snp/). MAF usually refers to the frequency of alleles that are uncommon in a given population. Finally, an association with a rating of AAA was considered strong, while a rating of $\mathrm{C}$ for any of the three items was considered weak. All other ratings were considered moderate.

The FPRP is a Bayesian prophylactic against false reports of significant associations. The FPRP was calculated with the Excel spreadsheet on the Wacholder website (Wacholder et al., 2004). For FPRP calculations, the prior probability was preset to 0.05 , the FPRP noteworthiness value was 0.2 , and the statistical power of detecting an OR of 1.5 (for SNP with an increased risk) or an OR of 0.67 (for SNP with a decreased risk) was used, as described by Wacholder et al. (2004). If the FPRP value was less than 0.2 , the association was considered noteworthy, as the association might be true. The strength of FPRP was divided into the following three categories: FPRP $<0.05$, strong; $0.05<$ FPRP $<0.2$, moderate; and FPRP $>0.2$, weak. In order to more accurately evaluate the cumulative evidence, the Venice criteria and FPRP were combined. If the FPRP was rated as strong, the evidence strength determined with the Venice criteria was upgraded from moderate to strong or from weak to moderate. Otherwise, if the FPRP was rated as weak, the evidence strength determined with the Venice criteria was downgraded from strong to moderate or from moderate to weak (Liu et al., 2017).

\section{RESULTS}

\section{Overall Characteristics}

Of the 3,065 records initially retrieved from the PubMed, Web of Science, and Embase databases, 1,774 (57.88\%) were retained after removing duplicates. Finally, 120 articles were included in the umbrella review (Figure 1), which referred to a total of 190 SNP. 
TABLE 1 | Criteria for evaluation of epidemiological credibility.

\section{Criteria}

Amount of evidence

$-$

-

Replication

$-$

$-$

Protection from bias

$-$

$-$

\section{Categories}

A: The sample size for the rarer genotype/allele in a meta-analysis is greater than 1000

B: The sample size for the rarer genotype/allele in a meta-analysis is 100-1000

C: The sample size for the rarer genotype/allele in a meta-analysis is less than 100

A: $I^{2}<25$ and $95 \% P l$ excluding the null value

B: $P^{2}<25$ and 95\% Pl including the null value, or $P^{2} 25-50 \%$

C: $R^{2}>50 \%$ or no nominally statistically significant association in a meta-analysis

A: The summary effect size (in the random-effects model) is greater than 1.15 or less than 0.87 , and the following four situations do not occur: 1) nominal statistical significance is lost with the exclusion of the first published study; 2) nominal statistical significance is lost with the exclusion of studies where HWE is violated; 3) small study effects; 4) excess significance bias

$\mathrm{B}$ : there is no evidence of bias that would invalidate an association, but important information is missing

C: the summary effect size (in the random-effects model) is $0.87-1.15$, or at least one of the following four situations occurs: 1) nominal statistical significance is lost with the exclusion of the first published study; 2) nominal statistical significance is lost with the exclusion of studies where HWE is violated; 3) small study effects; 4) excess significance bias
Records identified through database searching

PubMed ( $\mathrm{n}=777$ )

Web of Science $(\mathrm{n}=1341)$

Embase ( $\mathrm{n}=947)$
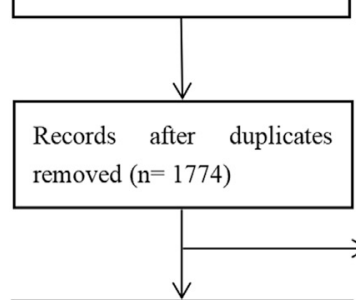

Records excluded by title and abstract $(n=900)$

Records screened according to title and abstract $(\mathrm{n}=874)$

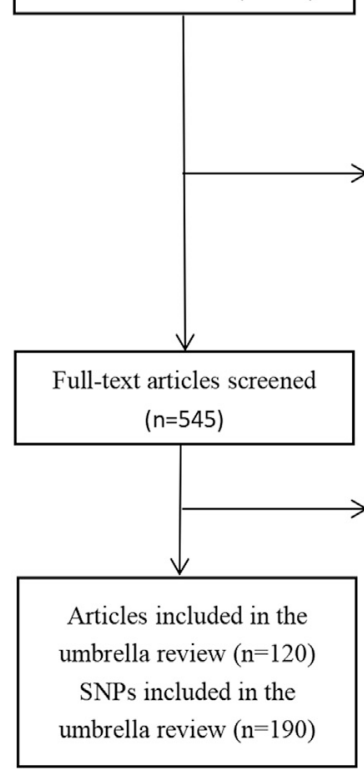

Records excluded based on the following reasons $(n=329)$

A: The number of studies was less than $3(n=212)$

B: Abstracts, letters or editorial comments $(n=24)$

C: Data were not available $(\mathrm{n}=24)$

D: Articles published in non-English $(\mathrm{n}=22)$

E: Don't investigate the association between SNPs and lung cancer risk $(n=20)$

F: Not systematic reviews or meta-analyses with quantitative synthesis $(n=18)$

G: Meta-analyses or systematic reviews based on individual data $(\mathrm{n}=6)$

$\mathrm{H}$ : Evaluating diagnosis, survival or recurrence of lung cancer $(\mathrm{n}=3)$

Investigating variants whose range was greater than single SNP, or not the latest systematic reviews and meta-analyses $(n=425)$

FIGURE 1 | The screening process of records. 


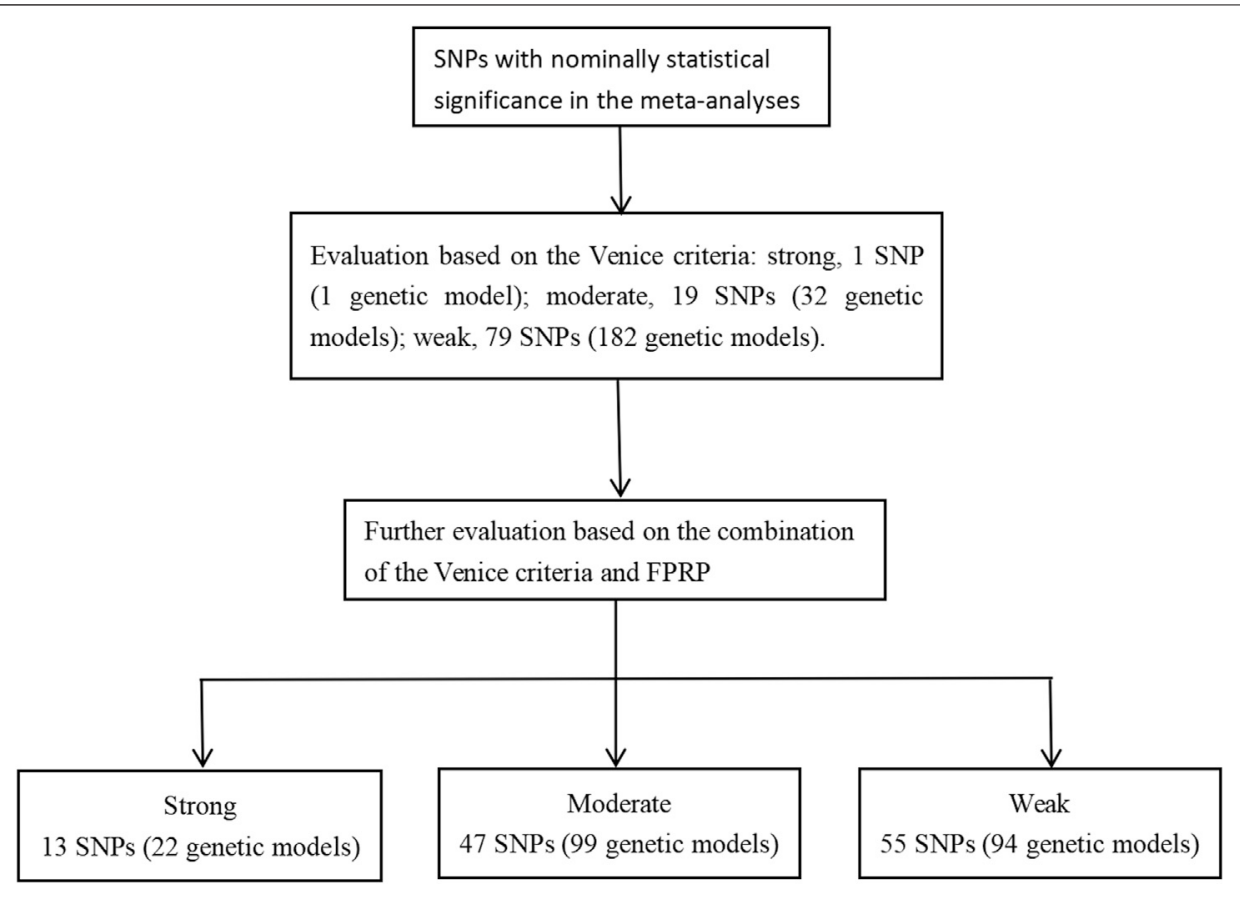

FIGURE 2 | The evaluation process of cumulative evidence.

The basic characteristics of the included articles are summarized in Supplementary Additional file S2. The majority of the included articles $(n=89,74.17 \%)$ were published since 2015 (range, 2008-2020). With respect to the epidemiological design, most of the meta-analyses (91.58\%) were synthesized by case-control studies as well as nested case-control studies. Some meta-analyses $(8.42 \%)$ also included the training set and validated set of GWAS. Included subjects were from many regions of the world, as shown in Supplementary Additional file S2 and Supplementary Additional file S3.

The quality of all included articles was assessed and the results were listed in Supplementary Additional file S2. Based on the AMSTAR score, $13(10.83 \%)$ of the included articles were considered as high quality, $99(82.50 \%)$ as moderate quality, and $8(6.67 \%)$ as low quality.

\section{Single Nucleotide Polymorphisms With Nominal Statistical Significance in the Meta-analyses}

A total of 85 SNP were nominally statistically associated with LC risk in at least one genetic model. Of these 85 SNP, 83 were located on 54 genes and two were located on two miRNAs. The median number of studies included in the meta-analyses was six (range, 3-52). The median number of cases, controls, and total sample size included in the meta-analyses were 3,173 (range, 402-55,353), 3,578 (range, 396-239 337), and 7,016 (range, 798-256 490), respectively (Supplementary Additional file S4).

The Venice criteria were used to assess the strength of evidence (Figure 2 and Supplementary Additional file S5). Only rs31489 (model 1) of the CLPTM1L gene was rated as strong evidence. A total of 32 genetic models of 19 SNP and 182 genetic models of 79 SNP were rated as moderate and weak evidence, respectively.

The Venice criteria and FPRP were combined to more accurately evaluate the cumulative evidence (Figure 2, Table 2, Table 3, and Table 4). There were 22 genetic models of 13 SNP with strong cumulative evidence. These 13 SNP were located on 11 genes and one miRNA. Among these 13 SNP, rs664143, rs31489, rs4646903 rs1048943, rs2308321, rs2735383, rs2736098, rs1800975, rs3213245, and rs12740674 were associated with an increased risk of LC, while rs2240308, rs938682, and rs2031920 were associated with a decreased risk. There were 47 SNP with moderate cumulative evidence that referred to 99 genetic models. Of these 47 SNP, 34 referring to 78 genetic models were associated with an increased risk of LC, whereas 13 SNP referring to 21 genetic models were associated with a decreased risk. In addition, 94 genetic models of 55 SNP were rated as weak cumulative evidence. However, 3 genetic models of 3 SNP could not be graded according to the Venice criteria and, therefore, were not assigned a final rating because the sample size of the rarer genotype in the meta-analyses could not be obtained directly or calculated based on the MAF.

\section{Single Nucleotide Polymorphisms Without Nominal Statistical Significance in the Meta-analyses}

A total of 148 SNP were not nominally statistically significant in at least one genetic model (Supplementary Additional file S6). Of these, 143 SNP were located on 83 genes, four were located on four miRNAs, and one was located on pre-miR-27a. The median number of studies included in the meta-analyses was five (range, 
TABLE 2 | Meta-analysis results of SNPs with the strong cumulative evidence based on the Venice criteria and FPRP.

\begin{tabular}{|c|c|c|c|c|c|c|c|c|}
\hline SNPs & Gene name & Variant & Genetic modle & The number of studies & $\mathrm{I}^{2}(95 \% \mathrm{Cl})$ & OR $95 \% \mathrm{Cl}$ (random effects) & $P(\mathrm{R})$ & $95 \% \mathrm{PI}$ \\
\hline rs664143 & ATM & $1 \mathrm{G} ; 2 \mathrm{~A}$ & 1 & 4 & $0.0(0,85)$ & $1.444(1.181,1.766)$ & $<0.001$ & $0.93,2.25$ \\
\hline rs2240308 & AXIN2 & $1 \mathrm{C} ; 2 \mathrm{~T}$ & 3 & 4 & $0.0(0,85)$ & $0.703(0.588,0.840)$ & $<0.001$ & $0.48,1.04$ \\
\hline rs938682 & CHRNA3 & $1 \mathrm{~T} ; 2 \mathrm{C}$ & 5 & 6 & $48.0(0,79)$ & $0.796(0.724,0.876)$ & $<0.001$ & $0.62,1.03$ \\
\hline rs31489 & CLPTM1L & $1 \mathrm{~A} ; 2 \mathrm{C}$ & 2 & 10 & $29.7(0,66)$ & $1.284(1.166,1.413)$ & $<0.001$ & $1.04,1.59$ \\
\hline- & - & - & 3 & 10 & $0.0(0,62)$ & $1.198(1.123,1.278)$ & $<0.001$ & $1.11,1.29$ \\
\hline rs4646903 & CYP1A1 & $1 \mathrm{C} ; 2 \mathrm{~T}$ & 2 & 41 & $35.1(5,56)$ & $1.395(1.161,1.676)$ & $<0.001$ & $0.69,2.82$ \\
\hline- & - & - & 5 & 41 & $41.1(14,59)$ & $1.172(1.085,1.265)$ & $<0.001$ & $0.85,1.62$ \\
\hline rs1048943 & CYP1A1 & 1 lle; $2 \mathrm{Val}$ & 4 & 37 & $39.0(9,59)$ & $1.626(1.313,2.013)$ & $<0.001$ & $0.73,3.64$ \\
\hline rs2031920 & CYP2E1 & $1 \mathrm{C} ; 2 \mathrm{~T}$ & 1 & 29 & $32.3(0,57)$ & $0.796(0.701,0.904)$ & $<0.001$ & $0.53,1.20$ \\
\hline- & - & - & 3 & 34 & $37.8(6,59)$ & $0.801(0.712 .0 .900)$ & $<0.001$ & $0.52,1.23$ \\
\hline rs2308321 & MGMT & 1 Ile; 2 Val & 1 & 5 & $0.0(0,79)$ & $1.198(1.082,1.326)$ & 0.001 & $1.02,1.41$ \\
\hline- & - & - & 3 & 5 & $8.9(0,81)$ & $1.191(1.063,1.335)$ & 0.003 & $0.95,1.50$ \\
\hline rs2735383 & NBS1 & $1 \mathrm{G} ; 2 \mathrm{C}$ & 3 & 4 & $0.0(0,85)$ & $1.187(1.067,1.321)$ & 0.002 & $0.94,1.50$ \\
\hline- & - & - & 4 & 4 & $10.0(0,86)$ & $1.275(1.109,1.466)$ & 0.001 & $0.89,1.83$ \\
\hline rs2736098 & TERT & $1 \mathrm{G} ; 2 \mathrm{~A}$ & 1 & 10 & $25.2(0,64)$ & $1.199(1.086,1.323)$ & $<0.001$ & $0.97,1.49$ \\
\hline- & - & - & 3 & 10 & $26.8(0,65)$ & $1.305(1.188,1.434)$ & $<0.001$ & $1.06,1.61$ \\
\hline rs1800975 & $X P A$ & $1 \mathrm{G} ; 2 \mathrm{~A}$ & 4 & 16 & $12.6(0,50)$ & $1.157(1.056,1.269)$ & 0.002 & $0.97,1.37$ \\
\hline rs3213245 & XRCC1 & $1 \mathrm{~T} ; 2 \mathrm{C}$ & 2 & 7 & $0.0(0,71)$ & $1.992(1.422,2.791)$ & $<0.001$ & $1.28,3.10$ \\
\hline- & - & - & 4 & 7 & $0.0(0,71)$ & $1.894(1.365,2.627)$ & $<0.001$ & $1.23,2.91$ \\
\hline rs12740674 & miR-1262 & $1 \mathrm{C} ; 2 \mathrm{~T}$ & 2 & 3 & $0.0(0,90)$ & $1.738(1.316,2.295)$ & $<0.001$ & $0.29,10.54$ \\
\hline- & - & - & 3 & 3 & $0.0(0,90)$ & $1.209(1.096,1.333)$ & $<0.001$ & $0.64,2.28$ \\
\hline- & - & - & 4 & 3 & $0.0(0,90)$ & $1.667(1.265,2.199)$ & $<0.001$ & $0.28,10.02$ \\
\hline
\end{tabular}

$P(R): p$ value of the random effect.

3-52). The median number of cases, controls, and total sample size included in the meta-analyses were 1,757 (range, 150-17,318), 2,063 (range, 204-35,755), and 3,858 (range, 354-39,445), respectively. Among these 148 SNP, 81 were not nominally statistically significant in any of the five genetic models.

\section{Sensitivity Analyses}

Sensitivity analyses of the corresponding models of SNP with the strong cumulative evidence (Supplementary Additional file S7) failed to find that the results were influenced by any single study, in addition to rs2308321 (models 1 and 3).

\section{DISCUSSION}

Based on the Venice criteria and FPRP, 13 SNP had strong cumulative evidence of associations with LC risk in at least one genetic model, $47 \mathrm{SNP}$ (in 99 genetic models) had moderate cumulative evidence, and 55 SNP (in 94 genetic models) had weak cumulative evidence. In general, the results of this umbrella review were not in very good agreement with the review by Liu et al. (2017) because the latter evaluated cumulative evidence of genetic polymorphisms and LC risk based on the existing meta-analysis results and relatively loose Venice criteria. The 13 SNP with strong cumulative evidence were located on 11 genes and one miRNA. Based on the predictions of the GSCALite website (http://bioinfo.life.hust.edu.cn/web/GSCALite/), eight (72.7\%) of these 11 genes (AXIN2, CHRNA3, CLPTM1L, CYP1A1, MGMT, NBS1, TERT, XPA) might be involved in one or more pathways related to LC (Liu et al., 2018).
The AXIN2 (axis inhibition protein 2) gene, also known as $A X I L$ and ODCRCS, is a negative regulator of the $\mathrm{Wnt} / \beta$-catenin signaling pathway that may play an important role in tumorigenesis (Kikuchi, 1999; Hughes and Brady, 2005). SNP rs2240308 is located in the AXIN2 coding region (exon1) at $17 q 24.1$, suggesting that $\mathrm{rs} 2240308$ may significantly influence AXIN2 gene expression. In the present umbrella review, rs2240308 was associated with susceptibility to LC, as suggested by the strong cumulative evidence in the dominant model. As compared with the CC genotype, the TT + CT genotype was associated with a significantly reduced risk of LC. However, the sample size of rs2240308 in the metaanalysis was relatively small, thus further investigations are necessary.

The CHRNA3 (cholinergic receptor nicotinic a3) gene, also known as LNCR2, PAOD2, BAIPRCK, and NACHRA3, encodes the $a 3 \mathrm{nAChR}$ (nicotinic acetylcholine receptor) subunit. A study by Paliwal et al. demonstrated that depletion and restoration of CHRNA3 expression induces and resists cell apoptosis, respectively (Paliwal et al., 2010). Moreover, Egleton et al. indicated that activation of nAChRs may act as tumor promoters to stimulate the development of LC cells and suppress apoptosis (Egleton et al., 2008). The SNP rs938682 of the CHRNA3 gene is located at 15q25.1. In the current umbrella review, rs938682 of the CHRNA3 gene had a strong cumulative evidence for the association with LC risk in the allele model. In contrast to the $\mathrm{T}$ allele, the $\mathrm{C}$ allele was associated with a reduced risk of $\mathrm{LC}$.

The CLPTM1L (cleft lip and palate transmembrane protein 1) gene, also known as CRR9, is a LC risk candidate gene that was found to be overexpressed in human lung tumor cell lines and lung tumors (James et al., 2012; Ni et al., 2012). SNP rs31489 of 
TABLE 3 | Cumulative evidence details of SNPs with the strong cumulative evidence based on the Venice criteria and FPRP.

\begin{tabular}{|c|c|c|c|c|c|c|c|c|}
\hline SNPs & $\begin{array}{l}\text { Genetic } \\
\text { modle }\end{array}$ & $\begin{array}{l}P \text { (Excluding the first } \\
\text { published study) }\end{array}$ & $\begin{array}{l}P \text { (Excluding studies with } \\
\text { the violated HWE) }\end{array}$ & $\begin{array}{l}\text { Small- } \\
\text { study } \\
\text { effect }\end{array}$ & $\begin{array}{c}\text { Excess } \\
\text { significance }\end{array}$ & $\begin{array}{l}\text { Venice } \\
\text { criteria }\end{array}$ & $\begin{array}{c}P \\
\text { (FPRP) }\end{array}$ & $\begin{array}{c}\text { Cumulative } \\
\text { evidence }\end{array}$ \\
\hline rs664143 & 1 & 0.018 & $<0.001$ & No & No & $\begin{array}{l}\text { Moderate (B/ } \\
\mathrm{B} / \mathrm{A})\end{array}$ & 0.010 & Strong \\
\hline rs2240308 & 3 & 0.001 & $<0.001$ & No & No & $\begin{array}{l}\text { Moderate }(\mathrm{B} / \\
\mathrm{B} / \mathrm{A})\end{array}$ & 0.003 & Strong \\
\hline rs938682 & 5 & 0.004 & $<0.001$ & No & No & $\begin{array}{l}\text { Moderate } \\
\left(A^{a} / B / A\right)\end{array}$ & $<0.001$ & Strong \\
\hline rs31489 & 2 & 0.005 & $<0.001$ & No & No & $\begin{array}{l}\text { Moderate }(\mathrm{A}) \\
\mathrm{B} / \mathrm{A})\end{array}$ & $<0.001$ & Strong \\
\hline- & 3 & 0.003 & $<0.001$ & No & No & $\begin{array}{l}\text { Strong }(A \\
A / A)\end{array}$ & $<0.001$ & Strong \\
\hline rs4646903 & 2 & 0.001 & 0.001 & No & No & $\begin{array}{l}\text { Moderate }(\mathrm{A} \\
\mathrm{B} / \mathrm{A})\end{array}$ & 0.009 & Strong \\
\hline- & 5 & $<0.001$ & $<0.001$ & No & No & $\begin{array}{l}\text { Moderate }(\mathrm{A} / \\
\mathrm{B} / \mathrm{A})\end{array}$ & 0.001 & Strong \\
\hline rs1048943 & 4 & $<0.001$ & 0.001 & No & No & $\begin{array}{l}\text { Moderate }(\mathrm{B} / \\
\mathrm{B} / \mathrm{A})\end{array}$ & 0.001 & Strong \\
\hline rs2031920 & 1 & $<0.001$ & 0.002 & No & No & $\begin{array}{l}\text { Moderate }(\mathrm{B} / \\
\mathrm{B} / \mathrm{A})\end{array}$ & 0.008 & Strong \\
\hline- & 3 & $<0.001$ & NA & No & No & $\begin{array}{l}\text { Moderate (B/ } \\
\mathrm{B} / \mathrm{B})\end{array}$ & 0.004 & Strong \\
\hline rs2308321 & 1 & 0.001 & 0.001 & No & No & $\begin{array}{l}\text { Moderate }(B / \\
A / A)\end{array}$ & 0.009 & Strong \\
\hline- & 3 & 0.005 & 0.003 & No & No & $\begin{array}{l}\text { Moderate }(\mathrm{B} / \\
\mathrm{B} / \mathrm{A})\end{array}$ & 0.049 & Strong \\
\hline rs2735383 & 3 & 0.002 & 0.002 & No & No & $\begin{array}{l}\text { Moderate }(\mathrm{A} / \\
\mathrm{B} / \mathrm{A})\end{array}$ & 0.031 & Strong \\
\hline- & 4 & $<0.001$ & 0.001 & No & No & $\begin{array}{l}\text { Moderate }(\mathrm{A} / \\
\mathrm{B} / \mathrm{A})\end{array}$ & 0.012 & Strong \\
\hline rs2736098 & 1 & 0.001 & $<0.001$ & No & No & $\begin{array}{l}\text { Moderate }(\mathrm{A} / \\
\mathrm{B} / \mathrm{A})\end{array}$ & 0.006 & Strong \\
\hline- & 3 & $<0.001$ & $<0.001$ & No & No & $\begin{array}{l}\text { Moderate }(\mathrm{A} / \\
\mathrm{B} / \mathrm{A})\end{array}$ & $<0.001$ & Strong \\
\hline rs1800975 & 4 & 0.003 & 0.015 & No & No & $\begin{array}{l}\text { Moderate }(\mathrm{A} / \\
\mathrm{B} / \mathrm{A})\end{array}$ & 0.036 & Strong \\
\hline rs3213245 & 2 & $<0.001$ & 0.008 & No & No & $\begin{array}{l}\text { Moderate }(B / \\
\text { AVA) }\end{array}$ & 0.023 & Strong \\
\hline- & 4 & 0.001 & 0.021 & No & No & $\begin{array}{l}\text { Moderate }(B / \\
\text { A A })\end{array}$ & 0.030 & Strong \\
\hline rs12740674 & 2 & NA & $<0.001$ & No & NO & $\begin{array}{l}\text { Mderate (B/ } \\
\mathrm{B} / \mathrm{B})\end{array}$ & 0.012 & Strong \\
\hline- & 3 & NA & $<0.001$ & No & No & $\begin{array}{l}\text { Moderate (B/ } \\
\mathrm{B} / \mathrm{B})\end{array}$ & 0.003 & Strong \\
\hline- & 4 & NA & $<0.001$ & No & No & $\begin{array}{l}\text { Moderate (B/ } \\
\mathrm{B} / \mathrm{B})\end{array}$ & 0.024 & Strong \\
\hline
\end{tabular}

NA: Not available;

${ }^{a}$ The sample size for the rarer allele in a meta-analysis was calculated based on the MAF offered by dbSNP of NCBI.

the CLPTM1L gene is located at 5p15.3. In this umbrella review, SNP rs31489 was strongly associated with susceptibility to LC in the homozygote comparison model and the dominant model. As compared to the AA genotype, the $\mathrm{CC}$ and $\mathrm{CC}+\mathrm{AC}$ genotypes were associated with an increased risk of LC.

The CYP1A1 (cytochrome P450 family 1 subfamily A member 1) gene, also known as $A H H, A H R R, C P 11, C Y P 1, C Y P I A 1, P 1-$ $450, P 450-C$, and $P 450 D X$, encodes a phase I enzyme that adjusts the metabolic activation of important tobacco procarcinogens, such as polycyclic aromatic hydrocarbons and aromatic amines, and might influence susceptibility to LC by regulating the metabolism of environmental carcinogens
(Guengerich and Shimada, 1998). The SNP rs4646903 and rs1048943 of the CYP1A1 gene, located at 15q24.1, are two importantly functional nonsynonymous SNP. In this umbrella review, relationships between rs4646903 and lung cancer risk had the strong cumulative evidence in the homozygote comparison model and the allele model. The TT genotype and T allele were associated with significantly higher risks of LC than the CC genotype and C allele, respectively. For rs1048943, associations between rs1048943 and LC risk with the strong cumulative evidence were in the recessive model. The $\mathrm{Val} / \mathrm{Val}$ genotype had an increased risk of LC, compared with the Ile/Ile + Ile/ Val genotype. 
TABLE 4 | Cumulative evidence details of SNPs with the moderate cumulative evidence based on the Venice criteria and FPRP.

\begin{tabular}{|c|c|c|c|c|c|c|c|c|c|}
\hline SNPs & $\begin{array}{l}\text { Gene } \\
\text { name }\end{array}$ & $\begin{array}{l}\text { Genetic } \\
\text { modle }\end{array}$ & $\begin{array}{c}P \text { (Excluding the } \\
\text { first published } \\
\text { study) }\end{array}$ & $\begin{array}{c}P \text { (Excluding } \\
\text { studies with the } \\
\text { violated HWE) }\end{array}$ & $\begin{array}{l}\text { Small- } \\
\text { study } \\
\text { effect }\end{array}$ & $\begin{array}{c}\text { Excess } \\
\text { significance }\end{array}$ & $\begin{array}{l}\text { Venice } \\
\text { criteria }\end{array}$ & $\begin{array}{c}P \\
\text { (FPRP) }\end{array}$ & $\begin{array}{c}\text { Cumulative } \\
\text { evidence }\end{array}$ \\
\hline rs8034191 & AGPHD1 & 1 & $<0.001$ & $<0.001$ & No & Yes & Weak (A/A/C) & $<0.001$ & Moderate \\
\hline- & - & 2 & $<0.001$ & $<0.001$ & No & Yes & Weak (A/B/C) & $<0.001$ & Moderate \\
\hline- & - & 3 & $<0.001$ & $<0.001$ & No & Yes & Weak (A/B/C) & $<0.001$ & Moderate \\
\hline- & - & 4 & $<0.001$ & $<0.001$ & No & Yes & Weak (A/A/C) & $<0.001$ & Moderate \\
\hline- & - & 5 & $<0.001$ & $<0.001$ & No & Yes & Weak (A/B/C) & $<0.001$ & Moderate \\
\hline rs931794 & AGPHD1 & 3 & 0.011 & 0.001 & Yes & Yes & $\begin{array}{c}\text { Weak (NA } \\
\text { B/C) }\end{array}$ & 0.012 & Moderate \\
\hline rs1760944 & APEX1 & 2 & 0.001 & $<0.001$ & No & Yes & Weak (A/A/C) & 0.001 & Moderate \\
\hline- & - & 4 & 0.007 & 0.001 & No & Yes & Weak (A/B/C) & 0.013 & Moderate \\
\hline- & - & 5 & 0.001 & $<0.001$ & No & Yes & Weak (A/A/C) & 0.002 & Moderate \\
\hline rs664143 & ATM & 2 & 0.005 & 0.001 & No & Yes & Weak (B/B/C) & 0.041 & Moderate \\
\hline- & - & 3 & 0.006 & $<0.001$ & No & Yes & Weak (B/B/C) & 0.006 & Moderate \\
\hline rs2240308 & AXIN2 & 1 & 0.011 & 0.005 & No & NO & $\begin{array}{c}\text { Moderate }(\mathrm{B} / \\
\mathrm{B} / \mathrm{A})\end{array}$ & 0.087 & Moderate \\
\hline- & - & 2 & $<0.001$ & $<0.001$ & Yes & Yes & Weak (B/B/C) & 0.007 & Moderate \\
\hline- & - & 4 & 0.001 & $<0.001$ & No & Yes & Weak (B/B/C) & 0.010 & Moderate \\
\hline- & - & 5 & $<0.001$ & $<0.001$ & Yes & Yes & Weak (A/A/C) & $<0.001$ & Moderate \\
\hline rs3117582 & BAT3 & 5 & $<0.001$ & NA & No & Yes & $\begin{array}{c}\text { Weak }\left(A^{a} /\right. \\
B / C)\end{array}$ & $<0.001$ & Moderate \\
\hline rs6983267 & CASC8 & 1 & 0.009 & 0.013 & No & No & $\begin{array}{c}\text { Moderate }(\mathrm{A} \\
\mathrm{B} / \mathrm{A})\end{array}$ & 0.193 & Moderate \\
\hline- & - & 2 & $<0.001$ & 0.001 & Yes & Yes & Weak (A/B/C) & 0.011 & Moderate \\
\hline- & - & 3 & 0.001 & 0.002 & Yes & Yes & Weak (A/B/C) & 0.032 & Moderate \\
\hline- & - & 5 & $<0.001$ & 0.001 & Yes & Yes & Weak (A/B/C) & 0.021 & Moderate \\
\hline rs151606 & CEP43 & 5 & NA & NA & No & NO & Weak (A/B/C) & 0.018 & Moderate \\
\hline rs12212247 & CEP43 & 5 & NA & NA & Yes & Yes & Weak (A/A/C) & 0.001 & Moderate \\
\hline rs1051730 & CHRNA3 & 2 & $<0.001$ & $<0.001$ & No & Yes & Weak (A/B/C) & $<0.001$ & Moderate \\
\hline- & - & 3 & $<0.001$ & NA & No & Yes & Weak (A/C/C) & $<0.001$ & Moderate \\
\hline- & - & 4 & $<0.001$ & $<0.001$ & No & Yes & Weak (A/A/C) & $<0.001$ & Moderate \\
\hline- & - & 5 & $<0.001$ & NA & No & Yes & Weak (A/B/C) & $<0.001$ & Moderate \\
\hline rs578776 & CHRNA3 & 5 & $<0.001$ & $<0.001$ & No & Yes & $\begin{array}{c}\text { Weak }\left(A^{a} /\right. \\
A / C)\end{array}$ & $<0.001$ & Moderate \\
\hline rs6495309 & CHRNA3 & 1 & 0.001 & $<0.001$ & No & Yes & Weak (A/A/C) & $<0.001$ & Moderate \\
\hline- & - & 2 & $<0.001$ & $<0.001$ & No & Yes & Weak (A/C/C) & 0.001 & Moderate \\
\hline- & - & 3 & $<0.001$ & $<0.001$ & No & Yes & Weak (A/B/C) & $<0.001$ & Moderate \\
\hline- & - & 5 & $<0.001$ & $<0.001$ & No & Yes & Weak (A/C/C) & 0.001 & Moderate \\
\hline rs16969968 & CHRNA5 & 1 & $<0.001$ & $<0.001$ & No & Yes & Weak (A/B/C) & $<0.001$ & Moderate \\
\hline- & - & 2 & $<0.001$ & $<0.001$ & No & Yes & Weak (A/A/C) & $<0.001$ & Moderate \\
\hline- & - & 3 & $<0.001$ & $<0.001$ & No & Yes & Weak (A/B/C) & $<0.001$ & Moderate \\
\hline- & - & 4 & $<0.001$ & $<0.001$ & No & Yes & Weak (A/A/C) & $<0.001$ & Moderate \\
\hline- & - & 5 & $<0.001$ & $<0.001$ & No & Yes & Weak (A/B/C) & $<0.001$ & Moderate \\
\hline rs402710 & CLPTM1L & 5 & $<0.001$ & NA & No & Yes & $\begin{array}{c}\text { Weak }\left(A^{a} /\right. \\
C / C)\end{array}$ & $<0.001$ & Moderate \\
\hline rs401681 & CLPTM1L & 5 & $<0.001$ & NA & No & Yes & $\begin{array}{c}\text { Weak }\left(A^{a} /\right. \\
A / C)\end{array}$ & $<0.001$ & Moderate \\
\hline rs31489 & CLPTM1L & 1 & 0.008 & $<0.001$ & No & Yes & Weak (A/A/C) & 0.005 & Moderate \\
\hline- & - & 4 & 0.009 & $<0.001$ & No & No & Weak (A/C/C) & 0.003 & Moderate \\
\hline- & - & 5 & 0.007 & $<0.001$ & No & Yes & Weak (A/C/C) & $<0.001$ & Moderate \\
\hline rs2453176 & CNOT6 & 5 & NA & NA & No & Yes & Weak (A/B/C) & 0.022 & Moderate \\
\hline rs231775 & CTLA-4 & 5 & 0.546 & $<0.001$ & No & No & Weak (A/B/C) & 0.008 & Moderate \\
\hline rs4646903 & CYP1A1 & 1 & 0.004 & 0.004 & No & No & $\begin{array}{c}\text { Moderate }(\mathrm{A} \\
\mathrm{B} / \mathrm{A})\end{array}$ & 0.052 & Moderate \\
\hline- & - & 3 & $<0.001$ & NA & No & No & Weak (A/C/B) & 0.002 & Moderate \\
\hline- & - & 4 & 0.008 & 0.004 & No & No & $\begin{array}{c}\text { Moderate }(\mathrm{A} \\
\mathrm{B} / \mathrm{A})\end{array}$ & 0.076 & Moderate \\
\hline rs1048943 & CYP1A1 & 2 & $<0.001$ & 0.001 & No & No & Weak $(B / C / A)$ & 0.004 & Moderate \\
\hline- & - & 5 & 0.001 & 0.002 & No & No & Weak (A/C/A) & 0.006 & Moderate \\
\hline rs1065852 & CYP2D6 & 4 & 0.002 & 0.258 & No & No & Weak (B/B/C) & 0.017 & Moderate \\
\hline rs4646904 & CYP4F3 & 5 & NA & NA & No & Yes & Weak (A/B/C) & 0.026 & Moderate \\
\hline rs12587742 & DCAF4 & 5 & NA & NA & No & Yes & Weak (A/B/C) & 0.036 & Moderate \\
\hline rs2240980 & DCAF4 & 5 & NA & NA & No & Yes & Weak (A/A/C) & $<0.001$ & Moderate \\
\hline rs13181 & ERCC2 & 1 & $<0.001$ & $<0.001$ & Yes & No & Weak (A/B/C) & $<0.001$ & Moderate \\
\hline
\end{tabular}


TABLE 4 | (Continued) Cumulative evidence details of SNPs with the moderate cumulative evidence based on the Venice criteria and FPRP.

\begin{tabular}{|c|c|c|c|c|c|c|c|c|c|}
\hline SNPs & $\begin{array}{l}\text { Gene } \\
\text { name }\end{array}$ & $\begin{array}{l}\text { Genetic } \\
\text { modle }\end{array}$ & $\begin{array}{c}P \text { (Excluding the } \\
\text { first published } \\
\text { study) }\end{array}$ & $\begin{array}{c}P \text { (Excluding } \\
\text { studies with the } \\
\text { violated HWE) }\end{array}$ & $\begin{array}{l}\text { Small- } \\
\text { study } \\
\text { effect }\end{array}$ & $\begin{array}{c}\text { Excess } \\
\text { significance }\end{array}$ & $\begin{array}{l}\text { Venice } \\
\text { criteria }\end{array}$ & $\begin{array}{c}P \\
\text { (FPRP) }\end{array}$ & $\begin{array}{c}\text { Cumulative } \\
\text { evidence }\end{array}$ \\
\hline- & - & 2 & 0.002 & $<0.001$ & Yes & No & Weak (A/B/C) & 0.020 & Moderate \\
\hline- & - & 3 & $<0.001$ & $<0.001$ & Yes & No & Weak (A/B/C) & $<0.001$ & Moderate \\
\hline- & - & 5 & $<0.001$ & $<0.001$ & Yes & No & Weak (A/C/C) & $<0.001$ & Moderate \\
\hline rs11549467 & $H I F-1 \alpha$ & 1 & 0.001 & 0.002 & No & No & Weak (C/B/A) & 0.046 & Moderate \\
\hline rs1800734 & $h M L H 1$ & 4 & $<0.001$ & 0.065 & No & Yes & Weak $(\mathrm{B} / \mathrm{B} / \mathrm{C})$ & 0.001 & Moderate \\
\hline rs2279744 & MDM2 & 4 & 0.020 & 0.005 & No & No & $\begin{array}{c}\text { Moderate }(\mathrm{A} \\
\mathrm{B} / \mathrm{A})\end{array}$ & 0.084 & Moderate \\
\hline rs2285053 & MMP2 & 5 & 0.228 & $<0.001$ & No & No & Weak (A/B/C) & 0.002 & Moderate \\
\hline rs11568818 & MMP7 & 1 & 0.117 & $<0.001$ & No & Yes & Weak (C/B/C) & 0.024 & Moderate \\
\hline- & - & 3 & 0.148 & $<0.001$ & No & Yes & Weak (C/B/C) & 0.016 & Moderate \\
\hline rs1801133 & MTHFR & 1 & 0.001 & 0.026 & Yes & No & Weak (A/C/C) & 0.021 & Moderate \\
\hline- & - & 2 & $<0.001$ & 0.003 & Yes & No & Weak (A/C/C) & 0.006 & Moderate \\
\hline- & - & 3 & $<0.001$ & 0.007 & Yes & No & Weak (A/C/C) & 0.006 & Moderate \\
\hline- & - & 5 & $<0.001$ & 0.005 & Yes & No & Weak (A/C/C) & 0.007 & Moderate \\
\hline rs2735383 & $N B S 1$ & 2 & $<0.001$ & $<0.001$ & No & Yes & Weak (A/B/C) & 0.001 & Moderate \\
\hline- & - & 5 & $<0.001$ & $<0.001$ & No & Yes & Weak (A/B/C) & 0.001 & Moderate \\
\hline rs1553232011 & $\begin{array}{c}\text { NEXN- } \\
\text { AS1 }\end{array}$ & 5 & NA & NA & Yes & Yes & Weak (A/B/C) & $<0.001$ & Moderate \\
\hline rs2890658 & $P D-L 1$ & 1 & $<0.001$ & $<0.001$ & Yes & Yes & Weak (C/B/C) & 0.001 & Moderate \\
\hline- & - & 3 & $<0.001$ & $<0.001$ & Yes & YEes & Weak (C/B/C) & $<0.001$ & Moderate \\
\hline- & - & 5 & $<0.001$ & $<0.001$ & Yes & Yes & Weak (B/B/C) & $<0.001$ & Moderate \\
\hline rs1800624 & RAGE & 2 & 0.073 & 0.001 & No & No & Weak (B/B/C) & 0.049 & Moderate \\
\hline rs2853677 & TERT & 1 & 0.001 & $<0.001$ & No & Yes & Weak (B/B/C) & 0.005 & Moderate \\
\hline- & - & 2 & $<0.001$ & $<0.001$ & No & Yes & Weak (B/A/C) & $<0.001$ & Moderate \\
\hline- & - & 3 & $<0.001$ & $<0.001$ & No & Yes & Weak (B/A/C) & $<0.001$ & Moderate \\
\hline- & - & 4 & 0.001 & $<0.001$ & No & Yes & Weak (B/B/C) & 0.006 & Moderate \\
\hline- & - & 5 & $<0.001$ & $<0.001$ & No & Yes & Weak (A/A/C) & $<0.001$ & Moderate \\
\hline rs2736100 & TERT & 1 & $<0.001$ & $<0.001$ & No & Yes & Weak (A/B/C) & $<0.001$ & Moderate \\
\hline- & - & 2 & $<0.001$ & $<0.001$ & No & Yes & Weak (A/C/C) & $<0.001$ & Moderate \\
\hline- & - & 3 & $<0.001$ & NA & No & Yes & Weak (A/C/C) & $<0.001$ & Moderate \\
\hline- & - & 4 & $<0.001$ & $<0.001$ & No & Yes & Weak (A/C/C) & $<0.001$ & Moderate \\
\hline- & - & 5 & $<0.001$ & NA & No & Yes & Weak (A/C/C) & $<0.001$ & Moderate \\
\hline rs2853669 & TERT & 2 & 0.014 & 0.002 & No & No & $\begin{array}{c}\text { Moderate(B/ } \\
\text { B/A) }\end{array}$ & 0.100 & Moderate \\
\hline- & - & 4 & 0.015 & $<0.001$ & No & Yes & Weak(B/B/C) & 0.005 & Moderate \\
\hline rs2736098 & TERT & 2 & $<0.001$ & $<0.001$ & No & Yes & Weak (A/A/C) & $<0.001$ & Moderate \\
\hline- & - & 4 & $<0.001$ & $<0.001$ & No & Yes & Weak (A/A/C) & $<0.001$ & Moderate \\
\hline- & - & 5 & $<0.001$ & $<0.001$ & No & Yes & Weak (A/A/C) & $<0.001$ & Moderate \\
\hline rs2853676 & TERT & 5 & 0.005 & 0.005 & No & No & Weak (A/B/C) & 0.030 & Moderate \\
\hline rs1544410 & VDR & 5 & $<0.001$ & 0.020 & Yes & No & Weak (A/C/C) & 0.021 & Moderate \\
\hline rs699947 & VEGF & 5 & 0.007 & 0.126 & No & No & Weak (A/C/C) & 0.048 & Moderate \\
\hline rs3213245 & $X R C C 1$ & 5 & 0.019 & 0.012 & No & Yes & Weak (A/C/C) & 0.038 & Moderate \\
\hline rs3769201 & ZAK & 5 & NA & NA & Yes & No & Weak (A/A/C) & $<0.001$ & Moderate \\
\hline rs722864 & ZAK & 5 & NA & NA & No & No & Weak (A/A/C) & $<0.001$ & Moderate \\
\hline rs12740674 & miR-1262 & 1 & NA & 0.003 & No & No & $\begin{array}{c}\text { Moderate(B/ } \\
\text { B/B) }\end{array}$ & 0.059 & Moderate \\
\hline- & - & 5 & NA & $<0.001$ & No & Yes & Weak (A/B/C) & $<0.001$ & Moderate \\
\hline rs2910164 & $m i R-146 a$ & 2 & 0.002 & 0.003 & Yes & No & Weak (A/C/C) & 0.046 & Moderate \\
\hline- & - & 4 & 0.001 & 0.001 & Yes & No & Weak (A/C/C) & 0.009 & Moderate \\
\hline- & - & 5 & $<0.001$ & 0.001 & Yes & No & Weak (A/C/C) & 0.004 & Moderate \\
\hline
\end{tabular}

NA: Not available;

${ }^{a}$ The sample size for the rarer allele in a meta-analysis was calculated based on the MAF offered by dbSNP of NCBI.

The MGMT (O-6-methylguanine-DNA methyltransferase) gene encodes a DNA repair protein that is vital to the repair of DNA damage induced by alkylating agents. Studies have demonstrated that MGMT plays an important role in the pathogenesis of cancers and might be a good biomarker candidate for early cancer detection (Gerson, 2004; Kaina et al., 2007). The SNP rs2308321, which is an important functional nonsynonymous $\mathrm{SNP}$, is mapped to exon 7 of the MGMT gene at $10 \mathrm{q} 26.3$. The results of this umbrella review found relationships between rs2308321 and lung cancer risk with the strong cumulative 
evidence were in the heterozygote comparison model and the dominant model. As compared to the Ile/Ile genotype, the Ile/Val and $\mathrm{Val} / \mathrm{Val}+\mathrm{Ile} / \mathrm{Val}$ genotypes were associated with a heightened risk of LC. Nevertheless, results of sensitivity analysis suggested that associations between rs 2308321 and LC risk in the heterozygote comparison model and the dominant model were not robust or stable. Thus, the meta-analysis of the associations between rs2308321 and LC risk should be updated in the future.

The NBS1 (Nijmegen breakage syndrome 1) gene, also known as NBN, ATV, NBS, P95, AT-V1, and $A T-V 2$, has an important influence on the cellular response to DNA damage and maintaining chromosomal integrity, which might influence oncogenesis (Kang et al., 2005; Falck et al., 2012). SNP rs 2735383 exists in the $3^{\prime}$-untranslated region of the NBS1 gene at $8 \mathrm{q} 21.3$. The current umbrella review demonstrated a strong association between rs2735383 and LC risk in the dominant model and recessive model. As compared to the GG genotype, the CC + GC genotype was associated with a high risk of LC, as was the CC genotype as compared to the GG + GC genotype.

The TERT (telomerase reverse transcriptase) gene, also known as TP2, TRT, CMM9, EST2, TCS1, hTRT, DKCA2, DKCB4, hEST2, and PFBMFT1, encodes the TERT protein, which is the catalytic subunit of telomerase and plays a vital role in the maintenance of telomere stability (Blackburn, 2001). Mutations to the TERT coding regions might influence telomere length and telomerase activity, which might further lead to substantially elevated cancer-related morbidity (Baird, 2010). The SNP rs2736098 of the TERT gene at 5p15.33 is a coding SNP. This umbrella review showed that there was a strong cumulative evidence on SNP rs2736098 and lung cancer risk in the heterozygote comparison model and the dominant model. In contrast to the GG genotype, the GA and GA + AA genotypes were associated with an increased risk of LC.

The XPA (xeroderma pigmentosum group A) gene, also known as $X P 1$ and $X P A C$, encodes the XPA protein, which is a DNA damage recognition and repair factor. As a zinc finger DNA binding protein, XPA is essential to nucleotide excision repair. So, a mutation to the XPA gene might be involved in oncogenesis (Fadda, 2016; Sugitani et al., 2016). SNP rs1800975 is localized to the $5^{\prime}$-untranslated region of XPA at $9 \mathrm{q} 22.33$. The current umbrella review found that rs1800975 was strongly associated with risk of LC in the recessive model. As compared to the GG + GA genotype, the AA genotype was associated with a high risk of LC.

Although the other three genes failed to be found in the LC pathway according to the prediction of the GSCALite website, they might influence the development of LC in other ways. The $A T M$ (ataxia telangiectasia mutated) gene, also known as AT1, $A T A, A T C, A T D, A T E, A T D C, T E L 1$, and TELO1, is a cancersusceptibility gene that encodes the ATM protein, which takes part in the identification and repair of DNA damage and cell cycle regulation. Thus, a mutation to the ATM gene might induce not only multiple system dysfunction, but also a concomitant increase in susceptibility to LC (Kruhlak et al., 2007; Xu et al., 2017). The SNP rs664143 of the ATM gene is located at 11q22.3. A study of Kim et al. showed that rs664143 exists in protein-binding motifs, which may become binding sites of intronic splicing repressors or enhancers (Kim et al., 2006). The results of this umbrella review found that SNP rs664143 was strongly associated with risk of LC in the heterozygote comparison model. As compared to the GG genotype, the GA genotype was associated with a significantly increased risk of LC. However, the sample size for analyzing associations between rs664143 and LC risk was relatively small, thus further investigations are necessary.

The CYP2E1 (cytochrome P450 family 2 subfamily E member 1) gene, also known as CPE1, CYP2E, P450-J, and P450C2E, encodes the CYP2E1 protein, which is an ethanol-inducible enzyme. CYP2E1 can metabolically activate various carcinogens, including benzene and $\mathrm{N}$-nitrosamines in tobacco, and thus might play a vital role in the development of LC (Peter Guengerich and Avadhani, 2018; Guengerich, 2020). SNP rs2031920 of the CYP2E1 gene is mapped to 10q26.3. In this umbrella review, rs2031920 was strongly associated with susceptibility to LC in the heterozygote comparison model and the dominant model. In contrast to the CC genotype, the CT and TT + CT genotypes were associated with a decreased risk of LC.

The XRCC1 (X-ray repair cross complementing 1) gene, also known as RCC and SCAR26, encodes a DNA repair protein that can interact with DNA components at damage sites to fix DNA base damage and single-strand breaks (Hanssen-Bauer et al., 2012). Therefore, XRCC1 plays a crucial role in protecting against tumorigenesis. SNP rs3213245 of the XRCC1 gene is located at 19q13.31. In the present umbrella review, rs3213245 was strongly associated with susceptibility to LC in the homozygote comparison model and the recessive model. In contrast to the TT genotype, the CC genotype was associated with increased susceptibility to LC, as was the CC genotype as compared to the TT + TC genotype.

Only one SNP located on miRNA (miR-1262) was strongly associated with an increased risk of LC. A previous study reported that miR-1262 on 1 p31.3 may suppress the proliferation of LC cells (Xie et al., 2017). SNP rs12740674 is located 61,743 bp downstream from miR-1262, which might map to a strong enhancer (Xie et al., 2017). The results of this umbrella review found strong associations between rs12740674 and risk of LC in the homozygote comparison model, the dominant model, and the recessive model. As compared to the CC genotype, the TT and CT + TT genotypes were associated with an increased risk of LC. Lastly, as compared to the CC + CT genotype, the TT genotype was associated with a high risk of LC.

In addition, 81 of the SNP identified in this umbrella review were not significantly correlated to LC risk in any of the five genetic models. Of these 81 SNP, 14 SNP on 12 genes had a sample size of more than 10,000, which included APEX1 (rs1130409), COX-2 (rs5275), EPHX1 (rs1051740, rs2234922), ERCC1 (rs11615), ERCC5 (rs17655), FASL (rs763110), MTHFR (rs1801131), NQO1 (rs1800566), TP53 (rs1042522, rs17878362), XPC (rs2228001), XRCC1 (rs25489), and XRCC3 (rs861539). According to the calculation results obtained with Quanto 1.2.4 software (https://preventivemedicine.usc.edu/downloadquanto/), 10,000 subjects provided approximately $80 \%$ statistical power if the incidence of LC was 200 per 100,000, OR was 1.15 , the genetic model was the dominant model, and the MAF was 0.1 . Therefore, further investigations of these 14 SNP might not be very productive. 
There were certain advantages to this umbrella review. This is the first umbrella review that extracted data, rather than the results, of systematic reviews and meta-analyses to calculate and evaluate the associations between SNP and LC risk. Moreover, the combined use of the Venice criteria and FPRP increased the reliability of the assessment results. However, there were some limitations. First, subgroup analysis stratified by ethnicity was not conducted because if an umbrella review of a specific ethnicity was included, the most recent meta-analysis referring to this ethnicity must be screened again. Hence, another umbrella review of a specific ethnicity is planned in the future. Second, the quality of included meta-analyses varied to a certain extent, which might lead to data credibility issues. Third, grey literature was not included in this umbrella review.

In conclusion, this umbrella review found strong cumulative evidence of associations of 13 SNP (of 11 genes and 1 miRNA) with LC risk, which provides important references for future studies on the relationships between SNP and LC risk.

\section{DATA AVAILABILITY STATEMENT}

The raw data supporting the conclusion of this article will be made available by the authors, without undue reservation.

\section{REFERENCES}

Baird, D. M. (2010). Variation at theTERTlocus and Predisposition for Cancer. Expert Rev. Mol. Med. 12, e16. doi:10.1017/s146239941000147x

Blackburn, E. H. (2001). Switching and Signaling at the Telomere. Cell 106 (6), 661-673. doi:10.1016/s0092-8674(01)00492-5

Carvalho, A. F., Köhler, C. A., Brunoni, A. R., Miskowiak, K. W., Herrmann, N., Lanctôt, K. L., et al. (2016). Bias in Peripheral Depression Biomarkers. Psychother Psychosom 85 (2), 81-90. doi:10.1159/000441457

DerSimonian, R., and Laird, N. (1986). Meta-Analysis in Clinical Trials. Controlled Clin. Trials 7 (3), 177-188. doi:10.1016/0197-2456(86)90046-2

Dong, L. M., Potter, J. D., White, E., Ulrich, C. M., Cardon, L. R., and Peters, U. (2008). Genetic Susceptibility to Cancer. Jama 299 (20), 2423-2436. doi:10.1001/jama.299.20.2423

Egger, M., Smith, G. D., Schneider, M., and Minder, C. (1997). Bias in MetaAnalysis Detected by a Simple, Graphical Test. Bmj 315 (7109), 629-634. doi:10.1136/bmj.315.7109.629

Egleton, R. D., Brown, K. C., and Dasgupta, P. (2008). Nicotinic Acetylcholine Receptors in Cancer: Multiple Roles in Proliferation and Inhibition of Apoptosis. Trends Pharmacol. Sci. 29 (3), 151-158. doi:10.1016/j.tips.2007.12.006

Fadda, E. (2016). Role of the XPA Protein in the NER Pathway: A Perspective on the Function of Structural Disorder in Macromolecular Assembly. Comput. Struct. Biotechnol. J. 14, 78-85. doi:10.1016/j.csbj.2015.11.007

Falck, J., Forment, J. V., Coates, J., Mistrik, M., Lukas, J., Bartek, J., et al. (2012). CDK Targeting of NBS1 Promotes DNA-End Resection, Replication Restart and Homologous Recombination. EMBO Rep. 13 (6), 561-568. doi:10.1038/ embor.2012.58

Gerson, S. L. (2004). MGMT: Its Role in Cancer Aetiology and Cancer Therapeutics. Nat. Rev. Cancer 4 (4), 296-307. doi:10.1038/nrc1319

Giannakou, K., Evangelou, E., and Papatheodorou, S. I. (2018). Genetic and NonGenetic Risk Factors for Pre-Eclampsia: Umbrella Review of Systematic Reviews and Meta-Analyses of Observational Studies. Ultrasound Obstet. Gynecol. 51 (6), 720-730. doi:10.1002/uog.18959

Guengerich, F. P., and Shimada, T. (1998). Activation of Procarcinogens by Human Cytochrome P450 Enzymes. Mutat. Res. 400 (1-2), 201-213. doi:10.1016/ s0027-5107(98)00037-2

\section{AUTHOR CONTRIBUTIONS}

$\mathrm{QW}, \mathrm{YZ}$, and $\mathrm{BZ}$ conceived and designed the study; XL performed literature search; XL, YL, JL, and QC carried out data extraction; XL and QW performed statistical analysis; XL and QW drafted the manuscript; YZ and BZ critically revised the manuscript.

\section{FUNDING}

This work was supported by National Key R\&D Program of China (No. 2017YFC0907401 to YZ), the LiaoNing Revitalization Talents Program (No. XLYC1907102 to QW and No. XLYC1802095 to YZ), National Natural Science Foundation of China (No. 81773524 to BZ) and 345 Talent Project of Shengjing Hospital of China Medical University (No. M0701 to XL and No. MJ0268 to QW).

\section{SUPPLEMENTARY MATERIAL}

The Supplementary Material for this article can be found online at: https://www.frontiersin.org/articles/10.3389/fmolb.2021.687105/ full\#supplementary-material

Guengerich, F. P. (2020). Cytochrome P450 2E1 and its Roles in Disease. ChemicoBiological Interactions 322, 109056. doi:10.1016/j.cbi.2020.109056

Hanssen-Bauer, A., Solvang-Garten, K., Akbari, M., and Otterlei, M. (2012). X-Ray Repair Cross Complementing Protein 1 in Base Excision Repair. Int. J. Mol. Sci. 13 (12), 17210-17229. doi:10.3390/ijms 131217210

Higgins, J. P. T., and Thompson, S. G. (2002). Quantifying Heterogeneity in a Meta-Analysis. Statist. Med. 21 (11), 1539-1558. doi:10.1002/sim.1186

Higgins, J. P. T., Thompson, S. G., and Spiegelhalter, D. J. (2009). A Re-Evaluation of Random-Effects Meta-Analysis. J. R. Stat. Soc. Ser. A. Stat. Soc. 172 (1), 137-159. doi:10.1111/j.1467-985X.2008.00552.x

Hughes, T., and Brady, H. (2005). Cross-talk between pRb/E2F and Wnt/?-Catenin Pathways: E2F1 Induces Axin2 Leading to Repression of Wnt Signalling and to Increased Cell Death. Exp. Cel Res. 303 (1), 32-46. doi:10.1016/ j.yexcr.2004.09.014

Ioannidis, J. P. A. (2009). Integration of Evidence from Multiple Meta-Analyses: a Primer on Umbrella Reviews, Treatment Networks and Multiple Treatments Meta-Analyses. Can. Med. Assoc. J. 181 (8), 488-493. doi:10.1503/cmaj.081086

Ioannidis, J. P. A., Patsopoulos, N. A., and Evangelou, E. (2007). Uncertainty in Heterogeneity Estimates in Meta-Analyses. Bmj 335 (7626), 914-916. doi:10.1136/bmj.39343.408449.80

Ioannidis, J. P. A. (2005). Why Most Published Research Findings Are False. Plos Med. 2 (8), e124. doi:10.1371/journal.pmed.0020124

Ioannidis, J. P., Boffetta, P., Little, J., O’Brien, T. R., Uitterlinden, A. G., Vineis, P., et al. (2008). Assessment of Cumulative Evidence on Genetic Associations: Interim Guidelines. Int. J. Epidemiol. 37 (1), 120-132. doi:10.1093/ije/dym159

Ioannidis, J. P., and Trikalinos, T. A. (2007). An Exploratory Test for an Excess of Significant Findings. Clin. Trials 4 (3), 245-253. doi:10.1177/ 1740774507079441

James, M. A., Wen, W., Wang, Y., Byers, L. A., Heymach, J. V., Coombes, K. R., et al. (2012). Functional Characterization of CLPTM1L as a Lung Cancer Risk Candidate Gene in the 5p15.33 Locus. PLoS One 7 (6), e36116. doi:10.1371/ journal.pone. 0036116

Kaina, B., Christmann, M., Naumann, S., and Roos, W. P. (2007). MGMT: Key Node in the Battle against Genotoxicity, Carcinogenicity and Apoptosis Induced by Alkylating Agents. DNA Repair 6 (8), 1079-1099. doi:10.1016/ j.dnarep.2007.03.008 
Kang, J., Ferguson, D., Song, H., Bassing, C., Eckersdorff, M., Alt, F. W., et al. (2005). Functional Interaction of H2AX, NBS1, and P53 in ATM-Dependent DNA Damage Responses and Tumor Suppression. Mol. Cel Biol. 25 (2), 661-670. doi:10.1128/mcb.25.2.661-670.2005

Kikuchi, A. (1999). Modulation of Wnt Signaling by Axin and Axil. Cytokine Growth Factor. Rev. 10 (3-4), 255-265. doi:10.1016/s1359-6101(99)00017-9

Kim, J. H., Kim, H., Lee, K. Y., Choe, K.-H., Ryu, J.-S., Yoon, H. I., et al. (2006). Genetic Polymorphisms of Ataxia Telangiectasia Mutated Affect Lung Cancer Risk. Hum. Mol. Genet. 15 (7), 1181-1186. doi:10.1093/hmg/ddl033

Kruhlak, M., Crouch, E. E., Orlov, M., Montaño, C., Gorski, S. A., Nussenzweig, A., et al. (2007). The ATM Repair Pathway Inhibits RNA Polymerase I Transcription in Response to Chromosome Breaks. Nature 447 (7145), 730-734. doi:10.1038/ nature 05842

Lau, J., Ioannidis, J. P., and Schmid, C. H. (1997). Quantitative Synthesis in Systematic Reviews. Ann. Intern. Med. 127 (9), 820-826. doi:10.7326/00034819-127-9-199711010-00008

Lau, J., Ioannidis, J. P., and Schmid, C. H. (1998). Summing up Evidence: One Answer Is Not Always Enough. The Lancet 351 (9096), 123-127. doi:10.1016/ s0140-6736(97)08468-7

Liu, C.-J., Hu, F.-F., Xia, M.-X., Han, L., Zhang, Q., and Guo, A.-Y. (2018). GSCALite: A Web Server for Gene Set Cancer Analysis. Bioinformatics 34 (21), 3771-3772. doi:10.1093/bioinformatics/bty411

Liu, C., Cui, H., Gu, D., Zhang, M., Fang, Y., Chen, S., et al. (2017). Genetic Polymorphisms and Lung Cancer Risk: Evidence from Meta-Analyses and Genome-wide Association Studies. Lung Cancer 113, 18-29. doi:10.1016/j.lungcan.2017.08.026

Malhotra, J., Malvezzi, M., Negri, E., La Vecchia, C., and Boffetta, P. (2016). Risk Factors for Lung Cancer Worldwide. Eur. Respir. J. 48 (3), 889-902. doi:10.1183/13993003.00359-2016

Marshall, A. L., and Christiani, D. C. (2013). Genetic Susceptibility to Lung CancerLlight at the End of the Tunnel? Carcinogenesis 34 (3), 487-502. doi:10.1093/carcin/ bgt016

Moher, D., Liberati, A., Tetzlaff, J., and Altman, D. G. (2009). Preferred Reporting Items for Systematic Reviews and Meta-Analyses: The PRISMA Statement. Plos Med. 6 (7), e1000097. doi:10.1371/journal.pmed.1000097

Nasim, F., Sabath, B. F., and Eapen, G. A. (2019). Lung Cancer. Med. Clin. North America 103 (3), 463-473. doi:10.1016/j.mcna.2018.12.006

Neuenschwander, M., Ballon, A., Weber, K. S., Norat, T., Aune, D., Schwingshackl, L., et al. (2019). Role of Diet in Type 2 Diabetes Incidence: Umbrella Review of MetaAnalyses of Prospective Observational Studies. Bmj 366, 12368. doi:10.1136/ bmj.12368

Ni, Z., Tao, K., Chen, G., Chen, Q., Tang, J., Luo, X., et al. (2012). CLPTM1L Is Overexpressed in Lung Cancer and Associated with Apoptosis. PLoS One 7 (12), e52598. doi:10.1371/journal.pone.0052598

Paliwal, A., Vaissière, T., Krais, A., Cuenin, C., Cros, M.-P., Zaridze, D., et al. (2010). Aberrant DNA Methylation Links Cancer Susceptibility Locus 15q25.1 to Apoptotic Regulation and Lung Cancer. Cancer Res. 70 (7), 2779-2788. doi:10.1158/0008-5472.Can-09-4550

Peter Guengerich, F., and Avadhani, N. G. (2018). Roles of Cytochrome P450 in Metabolism of Ethanol and Carcinogens. Adv. Exp. Med. Biol. 1032, 15-35. doi:10.1007/978-3-319-98788-0_2

Riley, R. D., Higgins, J. P. T., and Deeks, J. J. (2011). Interpretation of Random Effects Meta-Analyses. Bmj 342, d549. doi:10.1136/bmj.d549

Rivera, G. A., and Wakelee, H. (2016). Lung Cancer in Never Smokers. Adv. Exp. Med. Biol. 893, 43-57. doi:10.1007/978-3-319-24223-1_3

Shea, B. J., Grimshaw, J. M., Wells, G. A., Boers, M., Andersson, N., Hamel, C., et al. (2007). Development of AMSTAR: A Measurement Tool to Assess the
Methodological Quality of Systematic Reviews. BMC Med. Res. Methodol. 7, 10. doi:10.1186/1471-2288-7-10

Siegel, R. L., Miller, K. D., and Jemal, A. (2020). Cancer Statistics, 2020. CA A. Cancer J. Clin. 70 (1), 7-30. doi:10.3322/caac.21590

Stroup, D. F., Berlin, J. A., Morton, S. C., Olkin, I., Williamson, G. D., Rennie, D., et al. (2000). Meta-Analysis of Observational Studies in EpidemiologyA Proposal for Reporting. Jama 283 (15), 2008-2012. doi:10.1001/ jama.283.15.2008

Sugitani, N., Sivley, R. M., Perry, K. E., Capra, J. A., and Chazin, W. J. (2016). XPA: A Key Scaffold for Human Nucleotide Excision Repair. DNA Repair 44, 123-135. doi:10.1016/j.dnarep.2016.05.018

Torre, L. A., Bray, F., Siegel, R. L., Ferlay, J., Lortet-Tieulent, J., and Jemal, A. (2015). Global Cancer Statistics, 2012. CA: A Cancer J. Clinicians 65 (2), 87-108. doi: $10.3322 /$ caac. 21262

Trikalinos, T. A., Salanti, G., Khoury, M. J., and Ioannidis, J. P. A. (2006). Impact of Violations and Deviations in Hardy-Weinberg Equilibrium on Postulated Gene-Disease Associations. Am. J. Epidemiol. 163 (4), 300-309. doi:10.1093/ aje/kwj046

Vineis, P., Manuguerra, M., Kavvoura, F. K., Guarrera, S., Allione, A., Rosa, F., et al. (2009). A Field Synopsis on Low-Penetrance Variants in DNA Repair Genes and Cancer Susceptibility. J. Natl. Cancer Inst. 101 (1), 24-36. doi:10.1093/jnci/ djn437

Wacholder, S., Chanock, S., Garcia-Closas, M., El ghormli, L., and Rothman, N. (2004). Assessing the Probability that a Positive Report Is False: An Approach for Molecular Epidemiology Studies. J. Natl. Cancer Inst. 96 (6), 434-442. doi:10.1093/jnci/djh075

Xie, K., Chen, M., Zhu, M., Wang, C., Qin, N., Liang, C., et al. (2017). A Polymorphism in miR-1262 Regulatory Region Confers the Risk of Lung Cancer in Chinese Population. Int. J. Cancer 141 (5), 958-966. doi:10.1002/ ijc. 30788

Xu, Y., Gao, P., Lv, X., Zhang, L., and Zhang, J. (2017). The Role of the Ataxia Telangiectasia Mutated Gene in Lung Cancer: Recent Advances in Research. Ther. Adv. Respir. Dis. 11 (9), 375-380. doi:10.1177/ 1753465817725716

Yang, T., Li, X., Montazeri, Z., Little, J., Farrington, S. M., Ioannidis, J. P. A., et al. (2019). Gene-environment Interactions and Colorectal Cancer Risk: An Umbrella Review of Systematic Reviews and Meta-Analyses of Observational Studies. Int. J. Cancer 145 (9), 2315-2329. doi:10.1002/ijc.32057

Conflict of Interest: The authors declare that the research was conducted in the absence of any commercial or financial relationships that could be construed as a potential conflict of interest.

Publisher's Note: All claims expressed in this article are solely those of the authors and do not necessarily represent those of their affiliated organizations, or those of the publisher, the editors and the reviewers. Any product that may be evaluated in this article, or claim that may be made by its manufacturer, is not guaranteed or endorsed by the publisher.

Copyright (c) $2021 \mathrm{Li}, \mathrm{Wu}, \mathrm{Zhou}, \mathrm{Liu}, \mathrm{Lv}$, Chang and Zhao. This is an open-access article distributed under the terms of the Creative Commons Attribution License (CC $B Y$ ). The use, distribution or reproduction in other forums is permitted, provided the original author(s) and the copyright owner(s) are credited and that the original publication in this journal is cited, in accordance with accepted academic practice. No use, distribution or reproduction is permitted which does not comply with these terms. 